\title{
Barrier and facilitator on breastfeeding education and promotion: A literature review
}

\author{
Lina Handayani ${ }^{1}$, Maya Kusuma Dewi ${ }^{2}$, Lafi Munira ${ }^{3}$ \\ ${ }^{1,2}$ Faculty of Public Health, Universitas Ahmad Dahlan, Indonesia \\ ${ }^{3}$ College of Public Health Sciences, Chulalongkorn University, Thailand
}

\section{Article Info \\ Article history: \\ Received May 31, 2020 \\ Revised Aug 15, 2020 \\ Accepted Sep 14, 2020}

\section{Keywords:}

Barrier

Facilitator

Breastfeeding

Health education

Health promotion

\begin{abstract}
Breast milk contains many nutrients according to the needs of the baby for growth and development. Breast milk is very important for the health and well-being of infants. The world health organization recommends exclusive breastfeeding mothers for six months starting from the baby's first life and continuing until the age of two. Breastfeeding can provide economic benefits for the family and community. This study aimed to explore the barrier and facilitator on breastfeeding promotion and education. This study was literature study. This study finding that support from the baby's father is needed as a strong decision exclusively breastfeeding mothers. Pediatricians and midwives have an important role to support in providing exclusive breastfeeding from mothers and infants. Mothers who work full time find it very difficult to care for their babies exclusively. The workplace can be a barrier for mothers to care for and provide exclusive breastfeeding. Breastfeeding competency-based training is needed as a more optimal promotion of exclusive breastfeeding. Promotion of breastfeeding can increase the duration and exclusivity of breastfeeding. Knowledge promotes breastfeeding can increase the chances of successful breastfeeding and improve baby's health. An important role in the successful promotion of breastfeeding is the quality of knowledge and support for exclusive breastfeeding.
\end{abstract}

This is an open access article under the CC BY-SA license.

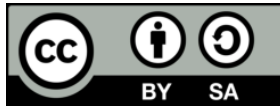

\section{Corresponding Author:}

Lina Handayani,

Faculty of Public Health,

Universitas Ahmad Dahlan,

Prof. Soepomo, UAD III, Umbulharjo, Yogyakarta, Indonesia.

Email: linafkm@gmail.com

\section{INTRODUCTION}

Breast milk is rich in nutrients with the right percentage according to the baby needs for growth and development [1]. Colostrum, a yellowish, sticky breast milk produced at the end of pregnancy, recommended by the World Health Organization is useful as a perfect food for newborns, and breastfeeding should start in the first hour after birth. Exclusive breastfeeding is recommended until the age of 6 months, and breastfeeding on an ongoing basis along with appropriate complementary foods up to the age of two years or more [2]. Breastfeeding is very important to maintain the health of the baby and the welfare of the baby who is growing and developing. This can be practiced, maintained, promoted continuously by all means [3].

World Health Organization recommends exclusive breastfeeding for the first six months of life and continues until the age of two years. Almost all mothers can breastfeed, provided they have accurate information, and support from family and community, and an adequate health care system [4]. 
Exclusive breastfeeding has an important role in determining optimal baby health and development, related to the reduced risk of disease in early life conditions, including otitis media, respiratory infections, diarrhea and early childhood obesity [5]. During the last decades, promotion of breastfeeding has increased by health systems in line with WHO and UNICEF policies and there have been numerous efforts to support, promote and retain breastfeeding [6]. Though wide educational programs and encouraging breastfeeding, the question that why such programs do not have significant progress remains unanswered. Research shows that breastfeeding is a complicated phenomenon and its successful accomplishment is affected by various demographic, physical, social and mental variables [7]. Shakespeare et al. argued that breastfeeding difficulties and mothers' lack of preparation to face them were barriers to success of breastfeeding and that mothers demanded support of health systems when encountering breastfeeding difficulties and help in finding a way to cope with them (8). In a study by Powell et al., participants referred to lack of work environment support for working nursing mothers as a barrier to breastfeeding. Findings of this study also showed that inadequate support of breastfeeding by hospital personnel as well as lack of instructions for mothers about difficulties of breastfeeding were causes of breastfeeding damage [8]. Educational programs about breastfeeding must be directed at both sexes, men and women [9]. Education and providing exclusive breastfeeding are investments that can produce very important changes to breastfeeding practices. This is the most efficient way to improve health [10]. This study objectives were to explore the breastfeeding promotion and education. By understand the situation and the importance of breastfeeding promotion and education, this study results can be used as recommendation on breastfeeding promotion and education improvement. Since it is important to explore the barriers to breastfeeding promotion based on experiences of mothers, families and health workers and identification of these barriers could be helpful in developing effective policies and implementing interventions in order to promote breastfeeding, this qualitative research was carried out to explore the barriers to breastfeeding promotion.

\section{RESEARCH METHOD}

This paper is based on literature review. An online literature search was conducted in PubMed, ScienceDirect, Pediatric Journal, Journal of Public Health, Advances in Epidemiology, Archives of Disease in Childhood, Society for Nutrition Journal, International Journal of Epidemiology, Public Health Nutrition, International Journal Nursing Research, Maternal and Child Health Journal, and National Public Health Journal. The search strategy included the following keywords: breastfeeding, breastfeeding education, and breastfeeding promotion. Search limits included: English and Indonesian language, but there were no limits for year of publication or study.

\section{RESULTS AND DISCUSSION}

Breastfeeding is the ideal method most suitable for meeting the physiological and psychological needs of a baby [5]. Exclusive breastfeeding at 6 months after birth can improve the growth and development of the baby, the health of the baby and the survival of the baby. Exclusive breastfeeding is one of the best and most natural forms of healing to avoid infection and disease [5]. Protection for infants especially at the age of 0-6 months is stronger compared to infants aged 7-12 months [1]. Breastfeeding can provide significant economic benefits for families and the community. Breastfeeding allows families to save more money than is spent on buying infant formula, other milk substitutes, and eating utensils [11] .

\subsection{Barriers on breastfeeding practice}

A mother decision to breastfeed her baby is exclusively influenced by various factors [12], this includes a mother decision to give breast milk to her baby and the success of doing so is largely influenced by the support she receives for breastfeeding [13]. Factors that do not allow mothers to breastfeed exclusively are mothers who have a young age, mothers who have poor emotions, and mothers who have babies with very low birth weight [14]. Breastfeeding is related to the hormone oxytocin and prolactin which can form a bond between mother and baby. Provision of breastfeeding guidance and counseling by health workers can be applied to gain knowledge about breastfeeding. Then the knowledge and skills about breastfeeding can provide psychological benefits for mothers and their babies, especially the satisfaction of mothers for breastfeeding can be a motivation for mothers to breastfeed for up to two years or more [15].

Mothers who give exclusive breast milk affect the initiation of breastfeeding and the duration of breastfeeding. It has a correlation with the knowledge, skills and experience of care, birth experience, maternal health and risk status of the mother and baby, and the nature of the initial interaction between mother and baby and a correlation with social and demographic [16]. Effective support that can be given to new mothers who are breastfeeding is a mother who is breastfeeding, herself or a friend who has knowledge 
and skills about breastfeeding [17]. Mothers who give birth to a child then do not immediately use contraception will risk an unplanned pregnancy. The risk is especially for mothers with 4 more children, limited knowledge about contraception, low ANC visits and low maternal economy [18].

Competency-based training is needed for optimal promotion and exclusive breastfeeding [19]. Duration of time 20 hours per week working mothers have a higher risk to stop breastfeeding [20]. Mothers who have the habit of smoking are less breastfeeding, and tend to breastfeed in a shorter time [14]. Mothers whose work in the health sector supports exclusive breastfeeding [21]. With this, mothers participate to help the family economy by giving exclusive breastfeeding to their babies. Mothers who work full time are 1.54 times less likely to give exclusive breastfeeding to their babies compared to mothers who are unemployed or unemployed [22]. Poor women are more likely to breastfeed exclusively, but they are also more likely to breastfeed with liquids or other solid foods other than formula milk at an early age [23]. The workplace can be a barrier for mothers who decide to care for and provide exclusive breastfeeding for their babies. Activities undertaken to promote breastfeeding should support breastfeeding initiation, although additional efforts are needed to increase breast milk consumption [14]. Mothers who have experienced success in breastfeeding before will have a better chance of being successful compared to someone who has a poor breastfeeding experience [14].

The sensitivity of a nursing mother can contribute to the improvement of a child cognitive ability, perhaps through fostering the intellectual development of the mother to the child. Mothers who breastfeed their babies can improve cognitive abilities and educational attainment in childhood [24]. Mothers who work full time find it very difficult to breastfeed their babies exclusively according to World Health Organization recommendations. Mothers who work full time have extensive knowledge about the practice of exclusive breastfeeding and its benefits but the full-time employment status and influence of family members weaken and hinder the practice of exclusive breastfeeding [25].

\subsection{Breastfeeding promotion when to start?}

In the transition period adolescents must be given motivation to support the social environment and improve the ability of adolescents to face difficulties [26]. Education about breastfeeding especially for adolescents is a strong foundation to overcome barriers to breastfeeding in the future when she becomes a mother [27]. Support and counseling for mothers is available routinely during antenatal care. It is used for maternal preparation at the time of the birth of the baby, to help the mother to start breastfeeding and to ensure that the mother has given breastfeeding exclusively in the postnatal period [3]. The positive attitude of mothers about breastfeeding and the initiation of breastfeeding in actively providing support during pregnancy. This includes during the perinatal and postnatal periods that can help mothers make the decision to breastfeed exclusively as a pattern of breastfeeding babies that are socially acceptable and respected in the community [28]. Postnatal care and personal health can increase knowledge and awareness of adolescent mothers and provide transitional experiences of teenage mothers [29].

All maternity units must be encouraged to make the strategic and practical changes needed to achieve the standard status of the Infant Friendly Hospital Initiative [30]. Early initiation of breastfeeding can sustain the period of breastfeeding until the baby weaning period [31]. Breastfeeding and early breastfeeding initiation are determinants of neonatal mortality for low birth weight in infants in Aceh Province, Indonesia. New strategies are needed to promote and increase the amount of low birth weight in infants who receive initiation of breastfeeding and exclusive breastfeeding. One effort is to organize annual low birth weight contests for infants in each district, where the assessment will be based on acceptance of breastfeeding initiation and exclusivity of breastfeeding for infants for infant growth and development [32].

Knowledge is used to enhance the promotion of breastfeeding in a variety of socioeconomic and cultural contexts [33]. Such knowledge can tailor cost-effective interventions with the aim of increasing the chances of lactation success and will ultimately improve infant health [34]. Knowledge alone is not enough because women often do not practice exclusive breastfeeding or wait up to 6 months for complementary feeding, even if they know about the benefits of breastfeeding [35]. The important role of successful efforts in the promotion of breastfeeding is the quality of knowledge and support from others [3]. Comprehensive breastfeeding education and support from a lactation consultant should begin in the prenatal period and continue into the postpartum period until the mother feels that she no longer needs that support [14].

General knowledge about breastfeeding is increasing among health care professionals thus causing more institutions to improve breastfeeding practices. Perceived barriers include difficulty and shame in public breastfeeding, problems maintaining personal identity while breastfeeding and women bodies in society [36]. The relationship between the length of a breastfeeding mother and the reason for the mother to wean her baby must have consideration for planning a breastfeeding campaign. Weaning a baby before the age of 12 months has nothing to do with cultural and socio-economic factors, but rather it is related 
to the illness of the child or mother and the mother's new pregnancy. To be able to avoid termination of breastfeeding in premature babies by providing appropriate health education and family planning to mothers who are breastfeeding [37].

\subsection{The Role of husband, health worker, and government policies support on breastfeeding practice}

Small families with 1-2 children have a positive influence on exclusive breastfeeding compared with large families with 3-5 children. This is a sign that mothers can provide exclusive breastfeeding by having fewer babies and having good birth spacing [5]. What has been proven to have a strong influence on the initiation and duration of breastfeeding is the support given by fathers through actively participating in the mother decision to breastfeed and by having positive knowledge and attitudes about the benefits and importance of breastfeeding exclusively [38]. The husband has a very important role in the mother decision to give exclusive breastfeeding to her baby [40]. Family support and a high level of husband education can help it in practicing exclusive breastfeeding [39].

Fathers will be given responsibility after the birth of the baby by asking for active cooperation in increasing infant feeding is an effective way that can improve the relationship of parents with their babies, form an interaction and social skills and can prevent children from emotional deprivation and child abuse. Fathers can consistently participate in care or support during breastfeeding [41]. To increase a mother breastfeeding rate, pediatricians must fulfill their responsibility to provide appropriate counseling and support for mothers who breastfeed their babies [42]. Most pediatricians believe that giving breast milk or formula is an acceptable method for breastfeeding a baby. In addition, the reason for not recommending mothers to breastfeed is because of medical conditions experienced such as inflammation of the breast tissue, problems with the nipple, low milk counts, jaundice and low weight gain in the mother despite having gone through therapies that do not prevent the mother from breastfeeding [43].

Government policies regarding maternity and maternity leave must reflect the needs of mothers in providing time with their babies before returning to work [5]. This legislative-based effort was undertaken to protect women rights to return to work and encourage female employees to have safe privacy to pump breast milk provided for their babies [44]. Law ensures that women have the time and freedom to pump breast milk or breastfeed a baby at work [45]. The participation of women workers should be encouraged to support breastfeeding and provide facilities for extortion at work for working mothers [46].

Efforts to disseminate initiation for breastfeeding within 1 hour after birth are a very important role given by nurses and midwives. In providing information and encouraging practices for breastfeeding initiation, they can be assisted by nurses or midwives who work in the field of public health. The strategy to be taken must include activities such as education on the practice of exclusive breastfeeding and nutrition education during pregnancy and breastfeeding. In addition, the policy made must promote breastfeeding in all hospitals in Indonesia. A delivery unit, health facilities for primary care and people working in hospitals must implement and use strategies to promote, protect and support mothers to breastfeed effectively [47].

Child nurse practitioners must provide breastfeeding management such as a mother's knowledge, skills and confidence. Breastfeeding can improve baby's health and provide economic benefits for a mother [48]. Promotion methods in companies that are used to create a policy to develop breastfeeding programs in the workplace using a top-down approach [49]. Efforts to improve breastfeeding practices exclusively can increase the increase in early breastfeeding initiation that can be provided through education and counseling by health workers [50].

Promotion of breastfeeding can increase the duration and degree of exclusivity of breastfeeding and reduce the risk of gastrointestinal tract infections and atopic eczema in the first year of a baby life [14]. The strategy undertaken for the greatest improvement in breastfeeding is hospital-based intervention, where counseling or medical personnel assistance beside the mother bed is offered to women immediately after giving birth to the baby [51]. Babies born in a baby-friendly hospital are more likely to be breastfed for a longer time than babies born in non-baby-friendly health facilities. The success of a mother in breastfeeding in a health facility can contribute to an increase in breastfeeding outcomes [52]. Breastfeeding can be a challenge, but the role of health workers is very important in supporting breastfeeding exclusively [53]. Bottle-fed infants should be avoided except in urgent situations especially for mothers who breastfeed and live in urban areas [54]. The intervention is a baby-friendly hospital initiative that can overcome obstacles in providing exclusive breastfeeding education, developing breastfeeding policies and helping mother's needs to increase exclusive breastfeeding in Indonesia [55].

Breastfeeding can be universal by being strengthened to protect, promote and support breastfeeding practices [56]. Maternal counseling during the initial obstetric visit will be more useful in influencing parent's choices for breastfeeding [57]. Support from a doctor and a mother mental health must receive attention. This is a factor that can be modified to promote sustainable breastfeeding. Counseling delivered by doctors is effective in promoting preventive health behaviors [58]. The incidence of gastrointestinal and 
respiratory diseases decreases after the promotion of effective breastfeeding at the community level. This can support a causal relationship, which indicates that breast milk itself or the process of breastfeeding provides protection against infant diseases [59]. Factors for success of breastfeeding promotion policies and programs include implementation of the International Code on Breastfeeding Marketing, Infant Friendly Hospital Initiatives, advocacy, training and education of health professionals, community-based promotion and support, maternity laws, and breastfeeding support at work [60].

\section{CONCLUSION}

Breastfeeding education is needed by mothers and families to know the benefits and importance of breastfeeding as well as to face and solve breastfeeding barriers and problem. Family support especially the baby's father is needed for nursing mothers. Exclusive breastfeeding can improve health status, prevent disease in infants, beneficial for the growth and development of infants. Promotion of exclusive breastfeeding can mainly be done by midwives and pediatricians during the process of pregnancy to childbirth which is the strength of the mother decision to breastfeed or not.

\section{REFERENCES}

[1] Prasetyo D., Sabaroedin IM., Ermaya YS., Soenarto Y., "Association Between Severe Dehydration In Rotavirus Diarrhea And Exclusive Breastfeeding Among Infants At Dr. Hasan Sadikin General Hospital, Bandung, Indonesia," Journal of Tropical Medicine, vol. 2015, pp. 1-4, 2015.

[2] World Health Organization. Obesity and overweight, 2012.

[3] Ekambaram M., Vishnu Bhat B., Ahamed MAP., "Knowledge, Attitiude and Practice Of Breastfeeding Among Postnatal Mothers," Current Pediatric Research, vol. 14, no. 2, pp. 119-24. 2010.

[4] Belakang AL. Word Health Organization (2002), pp. 1-6, 2004.

[5] Ekanem IA., Ekanem AP., Asuquo A., Eyo VO., "Attitude of Working Mothers to Exclusive Breastfeeding in Calabar Municipality, Cross River State, Nigeria,” Journal of Food Research, vol. 1, no. 2, pp. 71-5, 2012.

[6] Nelson AM., "A Metasynthesis of Qualitative Breastfeeding Studies," Journal of Midwifery \& Women's Health, vol. 51, no. 2, pp. e13-e20, 2006.

[7] Thulier D., Mercer J., "Variables Associated With Breastfeeding Duration," Journal of Obstetric, Gynecologic, \& Neonatal Nursing, vol. 38, no. 3, pp. 259-68, 2009.

[8] Shakespeare J., Blake F., Garcia J., "Breast-Feeding Difficulties Experienced By Women Taking Part In A Qualitative Interview Study Of Postnatal Depression,” Midwifery, vol. 20, no. 3, pp. 251-60, 2004.

[9] Hogan SE., "Overcoming barriers to breastfeeding: Suggested breastfeeding promotion programs for communities in eastern Nova Scotia," Canadian Journal of Public Health, vol. 92, no. 2, pp. 105-8, 2001.

[10] Horton S., Sanghvi T., Phillips M., Fiedler J., Perez-Escamilla R., Lutter C., et al., "Breastfeeding Promotion And Priority Setting In Health," Health Policy and Planning, vol. 11, no. 2, pp. 156-68, 1996.

[11] SWITT J., "From The Association," Journal of the American Dietetic Association, vol. 104, no. 10, pp. 1614-23, 2004.

[12] Newell H., The Impact of Breastfeeding Education: A Retrospective Look at Breastfeeding Education and Breastfeeding Rates A Retrospective Look at Breastfeeding Education \&amp, 2015.

[13] Grummer-Strawn LM, Rice SP, Dugas K, Clark LD, Benton-Davis S., "An Evaluation Of Breastfeeding Promotion Through Peer Counseling In Mississippi WIC Clinics," Maternal and Child Health Journal, vol. 1, no. 1, pp. 35-42, 1997.

[14] Jones JR, Kogan MD, Singh GK, Dee DL, Grummer-Strawn LM., "Factors Associated With Exclusive Breastfeeding In The United States," Pediatrics, vol. 128, no. 6, pp. 1117-25, 2011.

[15] Awaliyah SN, Rachmawati IN, Rahmah H., "Breastfeeding Self-Efficacy As a Dominant Factor Affecting Maternal Breastfeeding Satisfaction," BMC Nursing, vol. 18, no. S1, pp. 1-7, 2019.

[16] Barraclough B., "Major David Eilenberg," The New Zealand Medical Journal, vol. 125, no. 1364, pp. 52-5, 2012.

[17] Yngve A., Sjöström M., "Breastfeeding Determinants and a Suggested Framework For Action In Europe," Public Health Nutrition, vol. 4, no. 2b, pp. 729-39, 2001.

[18] Wilopo SA., Setyawan A., Pinandari AW., Prihyugiarto T., Juliaan F., Magnani RJ., "Levels, Trends And Correlates of Unmet Need For Family Planning Among Postpartum Women In Indonesia: 2007-2015," BMC Women's Health, vol. 17, no. 1, pp. 1-14, 2017.

[19] Cattaneo A., Yngve A., Koletzko B., Ruiz Guzman L., "Protection, promotion and support of breast-feeding in Europe: current situation on behalf of the "Promotion of Breastfeeding in Europe" project," Public Health Nutrition vol. 8, no. 1, pp. 39-46, 2016.

[20] Wyatt SN., "Challenges of the working breastfeeding mother. Workplace solutions," AAOHN Journal: Official Journal of The American Association of Occupational Health Nurses, vol. 50, no. 2, pp. 61-6, 2002.

[21] Al-Imari L., Hum S., Krueger P., Dunn S., "Breastfeeding During Family Medicine Residency," Family Medicine, vol. 51, no. 7, pp. 587-92, 2019.

[22] Sari Y., "Lack of Exclusive Breastfeeding among Working Mothers in Indonesia," Kesmas: National Public Health Journal, vol. 11, vol. 2, pp. 61-8, 2016. 
[23] Amanda Beatty, Nick Ingwersen, Clair Null, "Breastfeeding Practices and Knowledge In Indonesia," Mathematica Policy Research, pp. 1-7, July 2017.

[24] Britton JR., Britton HL., Gronwaldt V., "Breastfeeding, Sensitivity, And Attachment," Pediatrics, vol. 118, no. 5, pp. 1436-43, 2006.

[25] Danso J., "Examining the Practice of Exclusive Breastfeeding among Professional Working Mothers in Kumasi Metropolis of Ghana," International Journal of Nursing, vol. 1, no. 1, pp. 11-24. 2014.

[26] Erfina E., Widyawati W., McKenna L., Reisenhofer S., Ismail D., "Adolescent mothers' experiences of the transition to motherhood: An integrative review," International Journal of Nursing Sciences, vol. 6, no. 2, pp. 221-8, 2019.

[27] Moukarzel S., Abou Jaoudeh M., Farhat A., Saade M., Mamas C., Daly AJ., "Exploring the latitude of attitude: Intentions to breastfeed among adolescents in Lebanese schools," Maternal \& amp; Child Nutrition, pp. 1-10. August 2019.

[28] Ryan AS., "The resurgence of breastfeeding in the united states," Pediatrics, vol. 99, no. 4, p. 596, 1997.

[29] Erfina E., Widyawati W., McKenna L., Reisenhofer S., Ismail D., "Exploring Indonesian adolescent women's healthcare needs as they transition to motherhood: A qualitative study," Women and Birth, vol. 32, no. 6, pp. e544-e551, 2019.

[30] Broadfoot M., Britten J., Tappin D., MacKenzie J., "The Baby Friendly Hospital Initiative and breast feeding rates in Scotland," Archives of Disease in Childhood: Fetal and Neonatal Edition, vol. 90, no. 2, pp. 114-6, 2005.

[31] Permatasari TAE, Syafruddin A., "Early Initiation of Breastfeeding Related to Exclusive Breastfeeding and Breastfeeding Duration in Rural and Urban Areas in Subang, West Java, Indonesia," Journal of Health Research, vol. 30, no. 5, pp. 337-45, 2016.

[32] Berkat S., Sutan R., "The Effect of Early Initiation of Breastfeeding on Neonatal Mortality among Low Birth Weight in Aceh Province, Indonesia: An Unmatched Case Control Study," Advances in Epidemiology, vol. 2014, pp. 1-7, 2014.

[33] Pérez-Escamilla R., Curry L., Minhas D., Taylor L., Bradley E., "Scaling Up of Breastfeeding Promotion Programs in Low- and Middle-Income Countries: the "Breastfeeding Gear" Model," Advances in Nutrition, vol. 3, pp. 6, pp. 790-800, 2012.

[34] Perez-Escamilla R., Pollitt E., Lonnerdal B., Dewey KG., "Infant Feeding Policies In Maternity Wards And Their Effect On Breast- Feeding Success: An Analytical Overview," American Journal of Public Health, vol. 84, no. 1, pp. 89-97, 1994.

[35] Feldman-Winter L., Barone L., Milcarek B., Hunter K., Meek J., Morton J., et al., "Residency Curriculum Improves Breastfeeding Care," Pediatrics, vol. 126, no. 2, pp. 289-97, 2010.

[36] Earle S., "Factors Affecting The Initiation Of Breastfeeding: Implications for Breastfeeding Promotion," Health Promotion International, vol. 17, no. 3, pp. 205-14, 2002.

[37] Jakobsen MS., Sodemann M., Mølbak K., Aaby P., "Reason for Termination of Breastfeeding and The Length of Breastfeeding," International Journal of Epidemiology, vol. 25, no. 1, pp. 115-21, 1996.

[38] Pisacane A., Continisio GI., Aldinucci M., D’Amora S., Continisio P., "A Controlled Trial of The Father's Role In Breastfeeding Promotion," Pediatrics, vol. 116, no. 4, pp. e494-e498, 2005.

[39] Ratnasari D., Paramashanti BA., Hadi H., Yugistyowati A., Astiti D., Nurhayati E., "Family support and exclusive breastfeeding among Yogyakarta mothers in employment," Asia Pacific Journal of Clinical Nutrition, vol. 26, no. Suppl 1, pp. S31-5, 2017.

[40] Ryan AS., "The resurgence of breastfeeding in the united states," Pediatrics, vol. 99, no. 4, p. 596, 1997.

[41] Brown A., Davies R., "Fathers' experiences of supporting breastfeeding: Challenges for breastfeeding promotion and education," Maternal and Child Nutrition, vol. 10, no. 4, pp. 510-26, 2014.

[42] Freed GL, Clark SJ, Lohr JA, Sorenson JR., "Pediatrician Involvement In Breast-Feeding Promotion: A National Study Of Residents And Practitioners," Pediatrics, vol. 96, no. 3 I, pp. 490-4, 1995.

[43] Schanler RJ, O'Connor KG, Lawrence RA., "Pediatricians' Practices and Attitudes Regarding Breastfeeding Promotion," Pediatrics, vol. 103, no. 3, pp. 1-5, 1999.

[44] Ryan AS., Wenjun Z., Acosta A., "Breastfeeding Continues to Increase Into The New Millennium," Pediatrics, vol. 110, no. 6 I, pp. 1103-9, 2002.

[45] Murtagh L., Moulton AD., "Working Mothers, Breastfeeding, and The Law," American Journal of Public Health. vol. 101, no. 2, pp. 217-23, 2011.

[46] Sebayang SK., Dibley MJ, Astutik E., Efendi F., Kelly PJ., Li M., "Determinants of age-appropriate breastfeeding, dietary diversity, and consumption of animal source foods among Indonesian children," Maternal \&amp; Child Nutrition, vol. 16, no.1, pp. 1-19, 2020.

[47] Agushybana F., Siramaneerat I., Raksamat W., Siriphakhamongkhon S., "Population-based survey of exclusive breastfeeding in Indonesia: A secondary analysis," Pacific Rim International Journal of Nursing Research, vol. 22, no. 1, pp. 6-17, 2018.

[48] Brzezinski L., Mimm N., Porter S., "Pediatric Nurse Practitioner Barriers to Supporting Breastfeeding by Mothers and Infants," The Journal of Perinatal Education, vol. 27, no. 4, pp. 207-19, 2018.

[49] Basrowi RW, Sastroasmoro S., Sulistomo AW, Bardosono S., Hendarto A., Soemarko DS., et al., "Developing a Workplace Lactation Promotion Model In Indonesia Using Delphi Technique," Archives of Public Health, vol. 76, no. 1, pp. 1-9, 2018.

[50] Paramashanti BA, Hadi H., Alit Gunawan IM., "Timely Initiation Of Breastfeeding Is Associated With The Practice of Exclusive Breastfeeding In Indonesia,” Asia Pacific Journal of Clinical Nutrition, vol. 25, No. Suppl 1, pp. S52-6, 2016.

[51] Ahluwalia IB, Tessaro I., Grummer-Strawn LM, MacGowan C., Benton-Davis S., "Georgia's Breastfeeding Promotion Program For Low-Income Women,” Pediatrics, vol. 105, no. 6, p. E85, 2000. 
[52] Merten S., Dratva J., Ackermann-Liebrich U., "Do Baby-Friendly Hospitals Influence Breastfeeding Duration On a National Level?," Pediatrics, vol. 116, no. 5, 2005.

[53] Doherty T., Horwood C., Haskins L., Magasana V., Goga A., Feucht U., et al., "Breastfeeding Advice for Reality: Women's Perspectives On Primary Care Support In South Africa," Maternal \&amp; Child Nutrition, pp. 1-10, July 2019

[54] Hassan AA, Taha Z, Abdulla MA., Ali AAA, Adam I., "Assessment of bottle-feeding practices in kassala, eastern sudan: A community-based study,” Open Access Macedonian Journal of Medical Sciences, vol. 7, no. 4, pp. 651-6, 2019.

[55] Flaherman VJ., Chan S., Desai R., Agung FH., Hartati H., Yelda F., "Barriers to Exclusive Breast-Feeding In Indonesian Hospitals: A Qualitative Study of Early Infant Feeding Practices," Public Health Nutrition, vol. 21, no. 14, pp. 2689-97, 2018.

[56] Braun MLG, Giugliani ERJ, Soares MEM, Giugliani C., De Oliveira AP., Danelon CMM., "Evaluation of the Impact of the Baby-Friendly Hospital Initiative on Rates of Breastfeeding," American Journal of Public Health. vol. 93, no. 8, pp. 1277-9, 2003.

[57] Freed GL., Clark SJ., Lohr JA., Sorenson JR., "Pediatrician involvement in breast-feeding promotion: A national study of residents and practitioners," Pediatrics, vol. 96, no. 3 I, pp. 490-4, 1995.

[58] Taveras EM, Capra AM, Braveman PA., Jensvold NG., Escobar GJ, Lieu TA, et al., "Breastfeeding Discontinuation," Pediatrics, vol. 112, no. 1, pp. 108-15, 2003.

[59] Wright AL, Bauer M., Naylor A., Sutcliffe E., Clark L., "Increasing Breastfeeding Rates To Reduce Infant Illness At The Community Level.," Pediatrics, vol. 101, no. 5, pp. 837-44, 1998.

[60] Lutter CK, Morrow AL., Protection, Promotion, and Support and Global Trends in Breastfeeding," Advances in Nutrition, vol. 4, no. 2, pp. 213-9, 2013. 